\title{
SPEED REGULATOR AND HYSTERESIS BASED ON ARTIFICIAL INTELLIGENCE TECHNIQUES OF THREE-LEVEL DTC FOR INDUCTION MOTOR
}

\author{
Habib BENBOUHENNI*, Zinelaabidine BOUDJEMA** \\ ${ }^{*}$ Ecole Nationale Polytechnique d'Oran, Oran, Algeria, \\ E-mail: habib0264@gmail.com \\ ${ }^{* *}$ Université de Chlef, Chlef, Algeria, E-mail: boudjemaa1983@yahoo.fr
}

\begin{abstract}
Direct torque control (DTC) of induction motor (IM) is important in many applications. In this paper presents a three-level direct torque control is applied for IM using fuzzy-PI controller and hysteresis regulators based on artificial intelligence techniques. The DTC system is known to offer fast decoupled control between torque and flux via a simple control structure. Nevertheless, DTC system has two major drawbacks, with are the variable inverter switching frequency and high torque output ripple. The validity of the proposed control scheme is verified by simulation tests. The stator flux, torque, and current are determined and compared to the above technique.
\end{abstract}

Keywords: induction motor, DTC, fuzzy-PI, hysteresis regulators, three-level inverter, artificial intelligence techniques

\section{INTRODUCTION}

In Induction motors (IMs) are suitable electromechanical systems for a large spectrum of industrial applications. This is due to their high reliability, relatively low cost, and modest maintenance requirements. However, IMs are known as multivariable nonlinear timevarying systems. Thus makes their control so difficult, mainly in variable speed applications [1].

Recent advances in power semiconductor and microprocessor technology have made possible the application of advanced control techniques to alternating current (AC) motor drive systems [2].

There are two must common AC drives control schemes that are being widely researched. One of it is field oriented control (FOC) which was proposed by I. Takahashi and T. Noguchi. There are two major drawbacks of FOC compared to the DTC which are torque is controlled indirectly and requirement of the pulse encoder In FOC method of control the torque indirectly because its control priority is flux vector. FOC needs the pulse encoder in order to obtain the speed and position of the rotor. This makes the DTC system as an alternative and gained the attention of many researchers lately due to its simple structure by elimination of pulse encoder and simple algorithm with lesser dependency on motor parameters (only requires value of stator resistance $R_{s}$ and phase current). Over the past years, the utilization of multilevel inverter topology in the DTC system has gained popularity for the medium and high voltage applications [3].

Direct torque control, as one of the high-performance AC drives, was extended to the fieldof multi-level inverters in the late 20th century. DTC has a relatively simple control structure yetperforms at least as good as the FOC technique. It is also known that DTC drive is less sensitive toparameters de-tuning (only stator resistor is used to estimate the stator flux) and provides a high dynamicperformances than the classical vector control (fastest response of torque and flux) [4].

The multilevel inverter fed electric machine systems are considered as a promising approach in achieving high power/high voltage ratings. Moreover, multilevel inverters have the advantages of overcoming voltage limit capability of semiconductor switches, and improving 2 harmonic profilent of output waveforms. The output voltage waveform approaches a sine wave, thus having practically no common-mode voltage and no voltage surge to the motor windings. Furthermore, the reduction in $\mathrm{dv} / \mathrm{dt}$ can prevent motor windings and bearings from failure [5].

Many researches have been performed using the multilevel inverter and, for example, some articles described a novel DTC algorithm suited for a three level inverter, and proposed a very simple voltage balancing algorithm for the DTC scheme [4].

This paper is devoted to three-level inverter DTC 24 sectors with speed regulator and hysteresis based on artificial intelligence techniques of an IM. The present paper structure is as follows. Firstly, the model of the IM is presented in the second section. In the third section, the three-level inverter modeling is described. In the fourth section, the classical DTC strategy. Next, a breif introduction to the fuzzy and neural networks is presented in the fifth section. The sixth section introduces the threelevel DTC 24 sectors with speed regulators and hysteresis based in artificial intelligence approach. Finally, conclusion is drawn in the last section.

\section{MODEL OF INDUCTION MACHINE}

The model of IM in the $\alpha, \beta$ reference can be written in the following from $[6,7]$ :

$$
\left\{\begin{array}{c}
x(t)=A x(t)+B u(t) \\
y(t)=c x(t)
\end{array}\right.
$$

With:

$$
\begin{aligned}
& X=\left[\begin{array}{llll}
I_{s \alpha} & I_{s} \beta & \Phi_{s \alpha} & \Phi_{s \beta}
\end{array}\right]^{T}, U=\left[\begin{array}{llll}
v_{s} \alpha & v_{s} \beta & 0 & 0
\end{array}\right]^{T} \\
& T r=\frac{L_{r}}{R_{r}} ; \sigma=1-\frac{M^{2}}{L_{s} L_{r}} ; K=\frac{M}{\sigma L_{s} L_{r}} ; \lambda=\left[\frac{1}{T_{s}}+\frac{M^{2}}{T_{r} L_{s} L_{r}}\right]
\end{aligned}
$$




$$
A=\left[\begin{array}{cccc}
-\frac{\lambda}{\sigma} & 0 & \frac{\sigma}{T r} K & K w_{r} \\
0 & -\frac{\lambda}{\sigma} & -K w_{r} & \frac{\sigma K}{T r} \\
\frac{M}{T r} & 0 & \frac{-1}{T_{r}} & -w_{r} \\
0 & \frac{M}{T_{r}} & w r & \frac{-1}{T r}
\end{array}\right] ; B=\left[\begin{array}{cc}
\frac{1}{\sigma L_{S}} & \frac{1}{\sigma_{L_{S}}} \\
0 & 0 \\
0 & 0 \\
0 & 0
\end{array}\right] ; U=\left[\begin{array}{c}
v_{S} \alpha \\
v_{S} \beta \\
0 \\
0
\end{array}\right]
$$

\section{MODELING OF THE THREE-LEVEL INVERTER}

The three-level NPC inverter consists of twelve pairs of transistors-diodes and six clamping diodes (Fig. 1). The simple voltage of each phase is entirely defined by the state of the four transistors constituting each arm. The median diodes of each arm permits to have the zero level of the inverter output voltage. Only three sequences of operation are retained and done in work. Each arm of the inverter is modeled by a perfect switch with three positions $(0,1$, and 2$)$ [5].

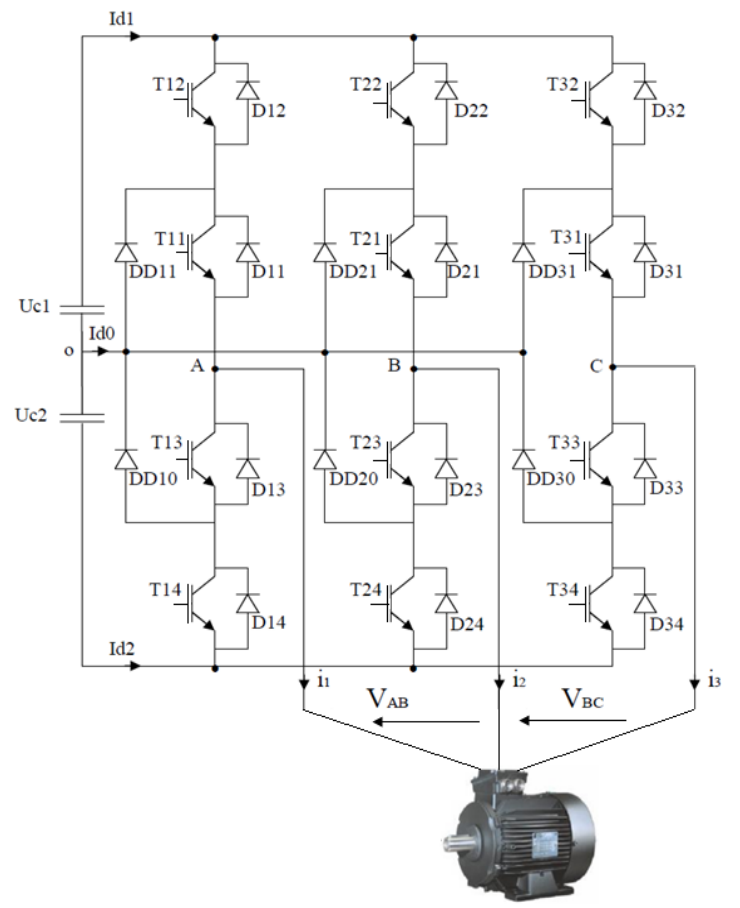

Fig. 1 Schematic diagram of a three-level inverter
The space vector diagram of a three-level inverter is shown in Fig. 2.

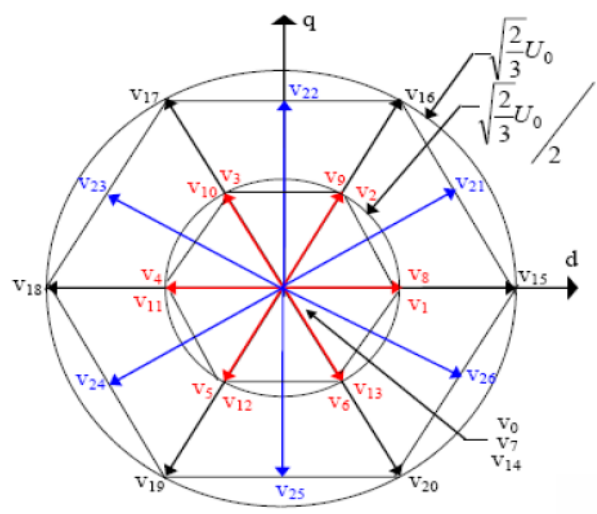

Fig. 2 Space vector diagram of three-level inverter

\section{DTC CONTROL}

The basic of DTC induction motor scheme is shown in Fig. 3. At each sample time, the two stator currents Isa and $I s b$ and the DC bus voltage $V d c$ are sampled. Using the inverter voltage vector, the $\alpha, \beta$ components of the stator voltage space vector in the stationary reference frame are calculated as follows [8].

The components of stator flux can be estimated by:

$$
\left\{\begin{aligned}
\Phi_{s \alpha}= & \int^{t}\left(v_{s \alpha}-R_{s} i_{s \alpha}\right) d t \\
& 0 \\
\Phi_{s \beta}= & \int_{0}^{t}\left(v_{s \beta}-R_{s} i_{s \beta}\right) d t
\end{aligned}\right.
$$

The stator flux amplitude is given by:

$$
\Phi_{s}=\sqrt{\Phi_{s \alpha}^{2}+\Phi_{s \beta}^{2}}
$$

The stator flux angle is calculated by:

$$
\theta_{S}=\operatorname{arctg}\left(\frac{\Phi_{s} \beta}{\Phi_{S \alpha}}\right)
$$

Electromagnetic torque equation is given by:

$$
T e=\frac{3}{2} p\left[\Phi_{s \alpha} i_{S \beta}-\Phi_{s \beta} i_{s \alpha}\right]
$$

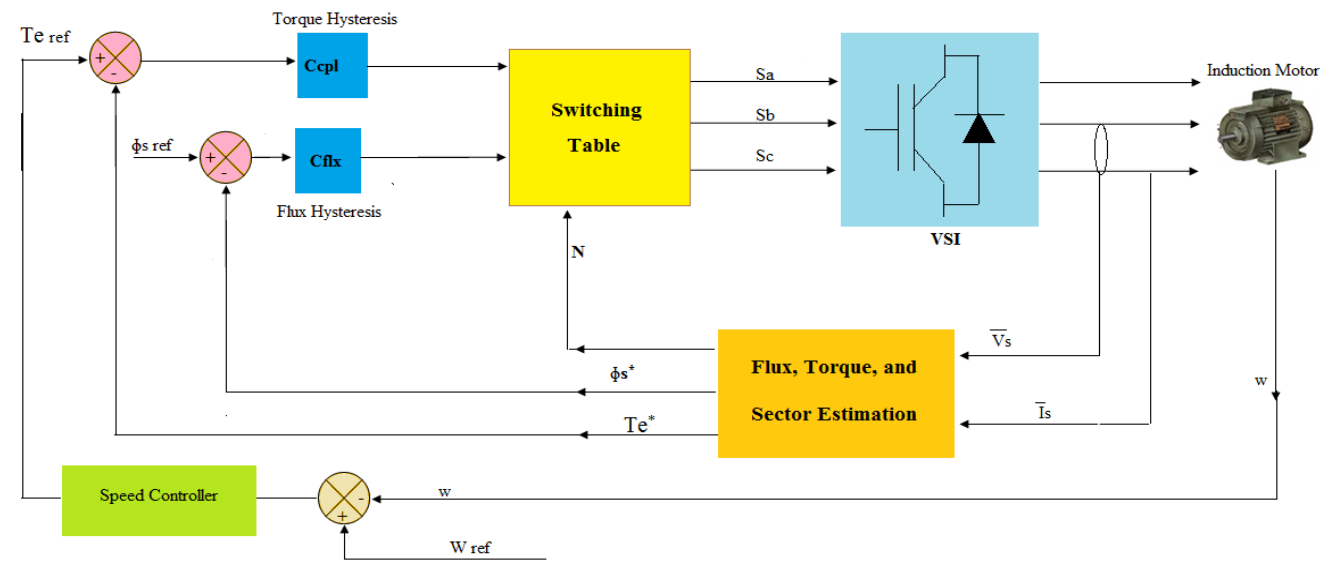

Fig. 3 Block diagram of DTC 
The error $\varepsilon_{\Phi}$ between the reference flux and its estimated value, respectively $\Phi_{S}$ and $\Phi_{S}{ }^{*}$, is used forinput to a comparator with hysteresis two-level figure (Fig. 4a).

Similarly, the error $\varepsilon_{T e}$ between the torque reference and its estimated value, respectively $T e^{*}$ et $\mathrm{Te}$, is used for input to a comparator with two-band upper and lower bands contained two (Fig. 4b). The output of each comparator, represented by variable signs $C f l x$ (or $C c p l$ ) indicates directly if the amplitude of the flux(or torque) must be increased or decreased to maintain these two variables within the hysteresis bands desired, $\Delta T e, \Delta \Phi s$.

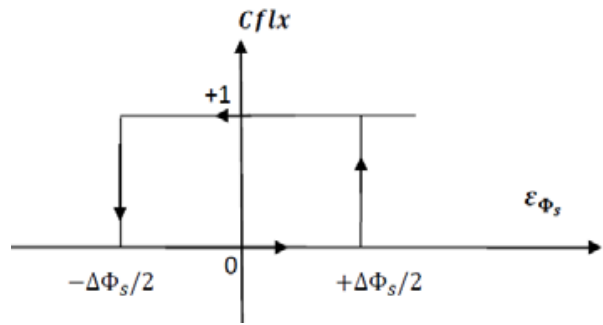

a) Stator flux

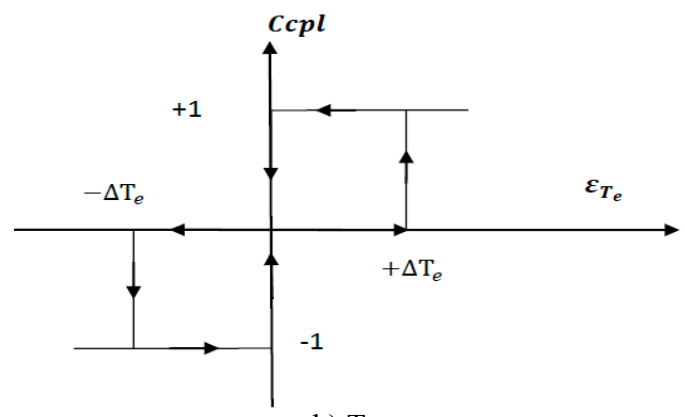

b) Torque

Fig. 4 Hysteresis comparators

Three-level torque and two-level flux hysteresis controllers are used according to the outputs of the torque controller and the sector information, appropriate voltage vectors for both the inverters are selected from a switching table as it is shown in Table 1.

Since none of the inverter switching vectors is able to generated the exact stator voltage required the to produce the desired changes in torque and flux, torque and flux ripples compose a real problem in DTC induction motor drive [8].

Table 1 Three-level DTC switching table with 24 sectors

\begin{tabular}{|c|c|c|c|c|c|c|}
\hline \multirow{3}{*}{$\mathbf{N}$} & \multicolumn{7}{|c|}{ Cflx } \\
\cline { 2 - 7 } & \multicolumn{7}{|c|}{$\mathbf{1}$} & $\mathbf{0}$ \\
\cline { 2 - 7 } & \multicolumn{7}{|c|}{$\mathbf{0}$} \\
\cline { 2 - 7 } $\mathbf{1}$ & 16 & 8 & 20 & 17 & 11 & 19 \\
\hline $\mathbf{2}$ & 16 & 8 & 20 & 17 & 11 & 19 \\
\hline $\mathbf{3}$ & 22 & 9 & 26 & 23 & 12 & 25 \\
\hline $\mathbf{4}$ & 22 & 9 & 26 & 23 & 12 & 25 \\
\hline $\mathbf{5}$ & 17 & 9 & 15 & 18 & 12 & 20 \\
\hline $\mathbf{6}$ & 17 & 9 & 15 & 18 & 12 & 20 \\
\hline $\mathbf{7}$ & 23 & 10 & 21 & 24 & 13 & 26 \\
\hline $\mathbf{8}$ & 23 & 10 & 21 & 24 & 13 & 26 \\
\hline $\mathbf{9}$ & 18 & 10 & 16 & 19 & 13 & 15 \\
\hline $\mathbf{1 0}$ & 18 & 10 & 16 & 19 & 13 & 15 \\
\hline $\mathbf{1 1}$ & 24 & 11 & 22 & 25 & 8 & 21 \\
\hline $\mathbf{1 2}$ & 24 & 11 & 22 & 25 & 8 & 21 \\
\hline $\mathbf{1 3}$ & 19 & 11 & 17 & 20 & 8 & 16 \\
\hline $\mathbf{1 4}$ & 19 & 11 & 17 & 20 & 8 & 16 \\
\hline $\mathbf{1 5}$ & 25 & 12 & 23 & 26 & 9 & 22 \\
\hline $\mathbf{1 6}$ & 25 & 12 & 23 & 26 & 9 & 22 \\
\hline $\mathbf{1 7}$ & 20 & 12 & 18 & 15 & 9 & 17 \\
\hline $\mathbf{1 8}$ & 20 & 12 & 18 & 15 & 9 & 17 \\
\hline $\mathbf{1 9}$ & 26 & 13 & 24 & 21 & 10 & 23 \\
\hline $\mathbf{2 0}$ & 26 & 13 & 24 & 21 & 10 & 23 \\
\hline $\mathbf{2 1}$ & 15 & 13 & 19 & 16 & 10 & 18 \\
\hline $\mathbf{2 2}$ & 15 & 13 & 19 & 16 & 10 & 18 \\
\hline $\mathbf{2 3}$ & 21 & 8 & 25 & 22 & 11 & 24 \\
\hline $\mathbf{2 4}$ & 21 & 8 & 25 & 22 & 11 & 24 \\
\hline & & & & & & \\
\hline
\end{tabular}

\section{DIRECT TORQUE CONTROL BASED ON ARTIFICIAL INTELLIGENCE STRATEGIES}

The principle of artificial intelligence techniques direct torque control is similar to traditional three-level DTC. However, the hysteresis controllers of torque and flux are replaced by the fuzzy controller and neural networks. The PI controller of speed is replaced by the fuzzy controller. The general structure of the IM with three-level DTC 24 sectors with artificial intelligence techniques is represented by Fig. 5 .

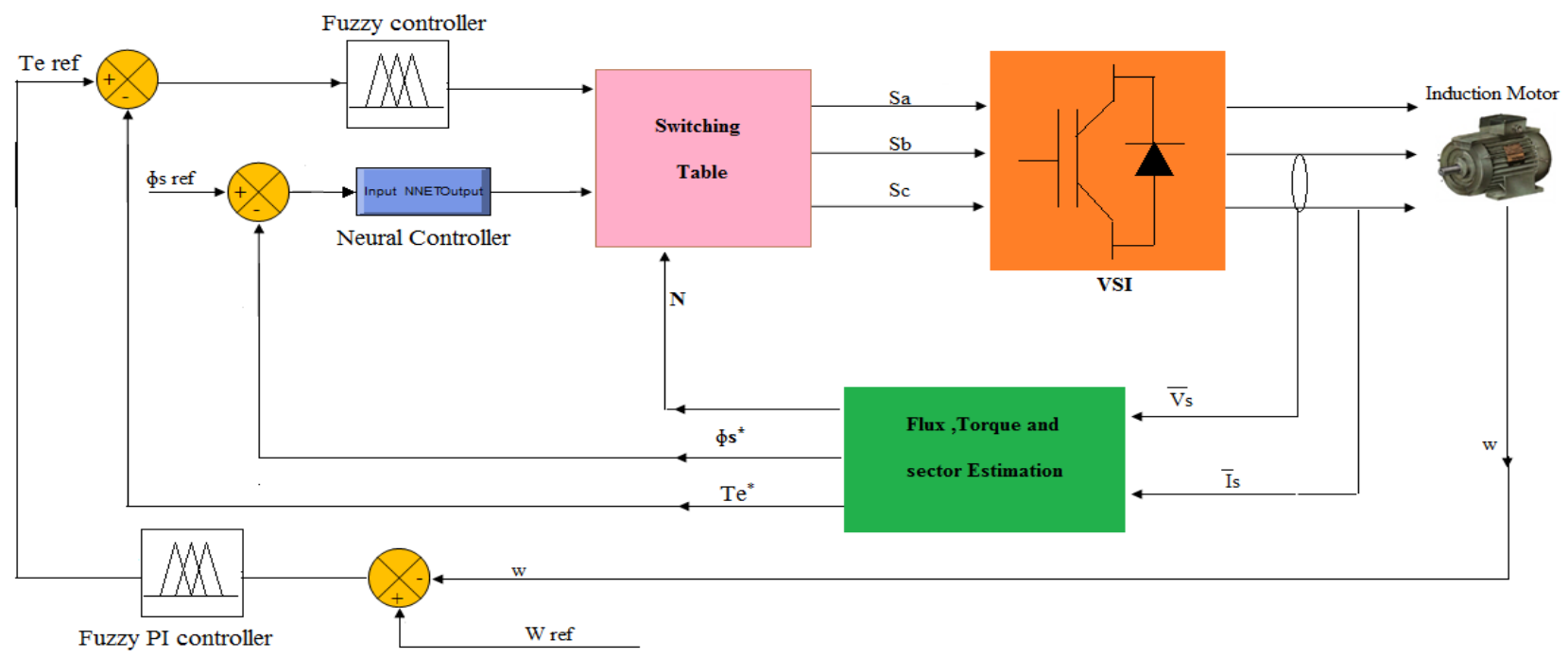

Fig. 5 Three-level DTC with 24 sectors based on artificial intelligence techniques of an induction motor 


\subsection{Hysteresis controller of flux based on neural networks}

Neural networks have self- adapting compatibilities whichmakes them well suited to handle non-linarites, uncertainness and parameter variations. A multilayer feed forward neuralnetwork constructs a global approximations to non-linear input-output mapping. Neural networks are capable of generalization in regions of the input space, where little or notraining data are available [9]. The structure of the proposedneural networks used in this paper, is shown in Fig. 6 .

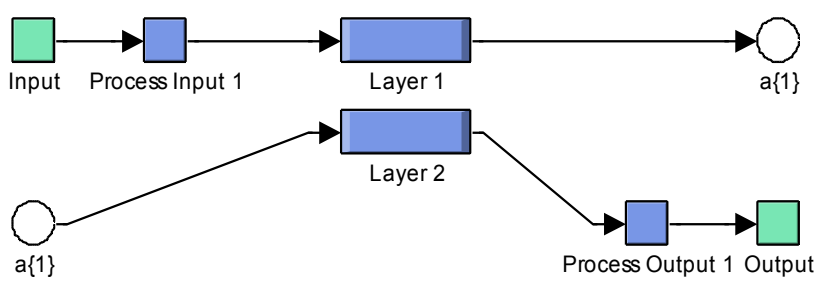

Fig. 6 Structure of proposed artificial neural networks

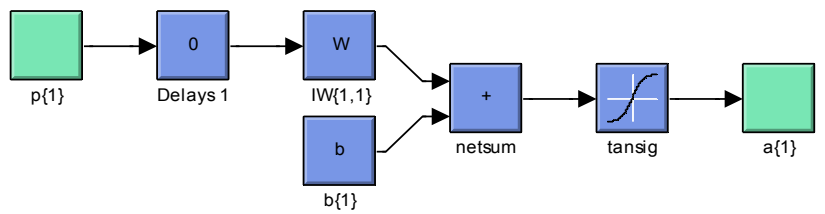

Fig. 7 Structure of layer 1

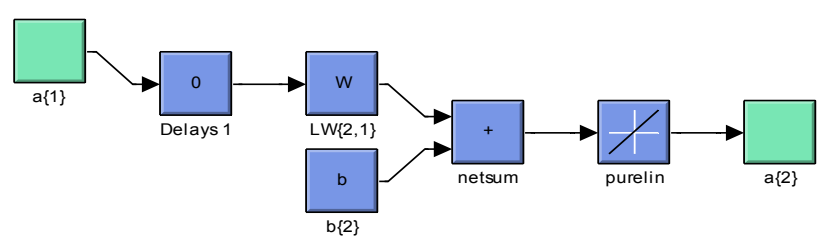

Fig. 8 Structure of layer 2

The proposed neural networks have three layers, i.e. inputlayer, hidden layer and the output layer.Input layer has 1 neuron, output layer has only one neuron and hidden layer has 3 neurons.

\subsection{Hysteresis controller of torque and PI controller based on fuzzy}

Fuzzy logic is recently getting increasing emphasis in drive control applications. Recent years, fuzzy logic control has found many applications in the past two decades. This is so largely increasing because fuzzy logic control has the capability to control nonlinear uncertain systems even in the case where no mathematical model is available for the control system [8].

The main preference of the fuzzy logic is that is easyto implement control that it has the ability of generalization [10]. The block diagram for fuzzy logic based speed regulator and torque hysteresis is shown in Fig. 9. The fuzzy logic rules are written by absorbing the performances of the PI controller and torque hysteresis.

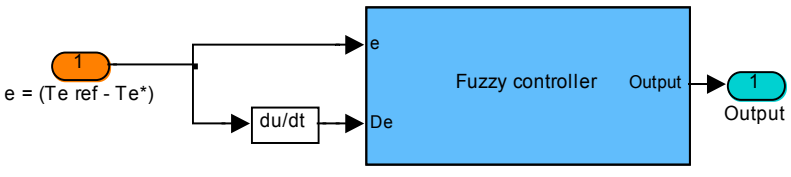

a) Fuzzy hysteresis of torque

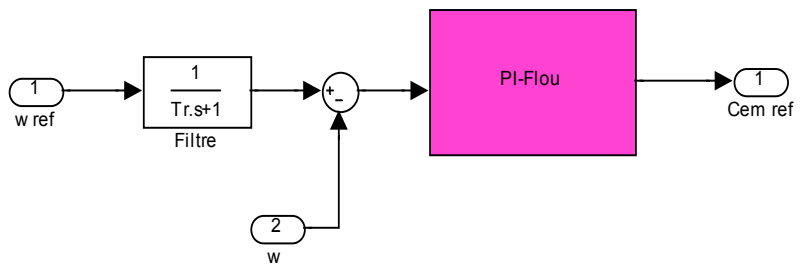

b) Fuzzy logic control of speed regulation

Fig. 9 Fuzzy control of speed and hysteresis controller

The membership function definition for the input variables "Error in speed and Error in torque hysteresis" is shown in Fig. 10a), "Change in Error of speed and torque hysteresis" is shown in Fig. 10b), "Output variable membership function" is shown in Fig. 10c) [11].

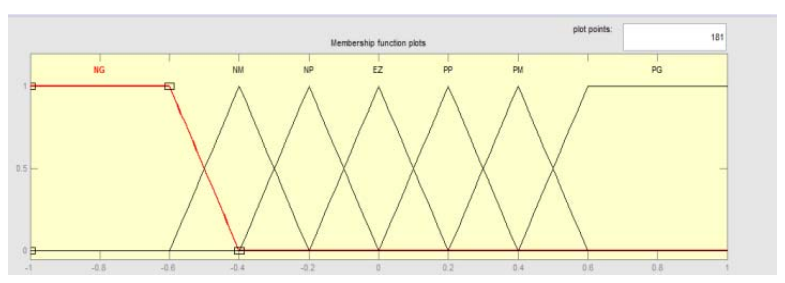

a) Error in speed and torque

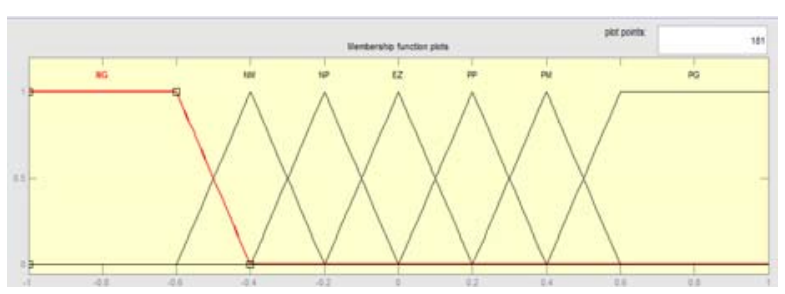

b) Change in error

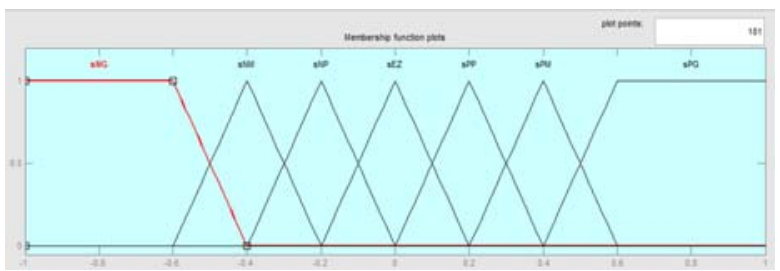

c) Output variable memership function

Fig. 10 Membership function for error, change in error and control of speed and hysteresis controller

The fuzzy logic rules for the proposed system are given in Table 2. 
Table 2 Fuzzy logic ruls of PI controller and torque hysteresis

\begin{tabular}{|c|l|l|l|l|l|l|l|}
\hline $\mathbf{e}$ & $\mathbf{N L}$ & $\mathbf{N M}$ & $\mathbf{N P}$ & $\mathbf{E Z}$ & $\mathbf{P S}$ & $\mathbf{P M}$ & PL \\
\cline { 1 - 6 }$\Delta \mathbf{e}$ & & & & & & & \\
\hline NL & NL & NL & NL & NL & NM & NP & EZ \\
\hline NM & NL & NL & NL & NM & NP & EZ & PS \\
\hline NP & NL & NL & NM & NP & EZ & PS & PM \\
\hline EZ & NL & NM & NP & EZ & PS & PM & PL \\
\hline PS & NM & NP & EZ & PS & PM & PL & PL \\
\hline PM & NP & EZ & PS & PM & PL & PL & PL \\
\hline PL & EZ & PS & PM & PL & PL & PL & PL \\
\hline
\end{tabular}

\section{SIMULATION RESULTS AND DISCUSSION}

The direct torque control with 24 sectors of an IM is implemented with simulation tools of MATLAB. The speed regulator is used as classical PI, fuzzy PI separately. The hysteresis controllers are used as neural hysteresis and fuzzy hysteresis. The performance analysis is done with speed, torque, flux, and current. The dynamic performance of the three-level DTC with 24 sectors of an induction motor is shown Fig. 11.

The dynamic performance of the three-level DTC with 24 sectors based on artificial intelligence techniques for the induction motor is shown Fig. 12.
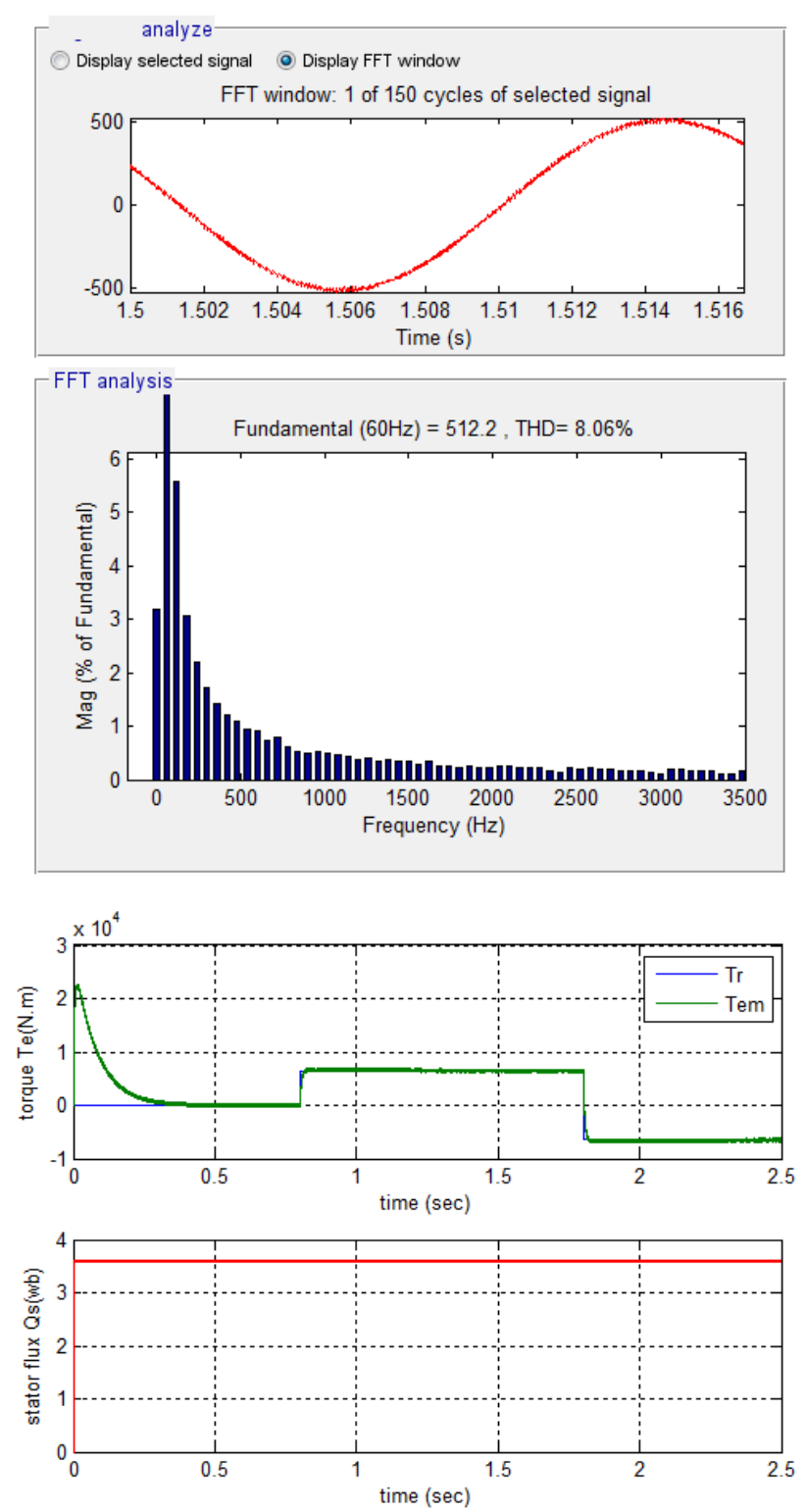
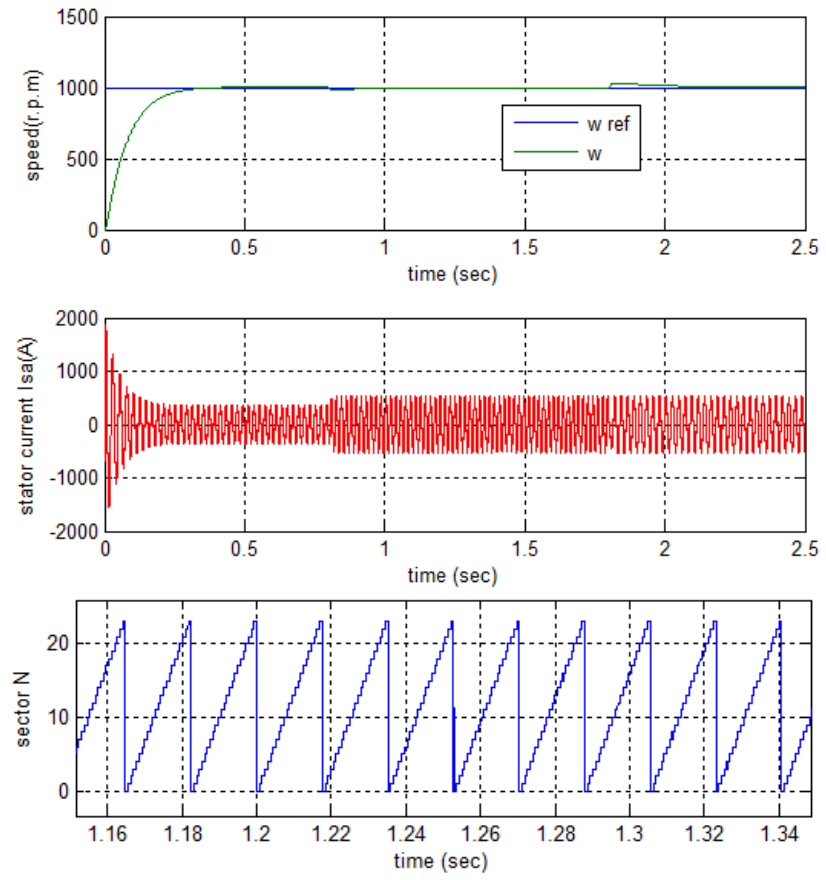

Fig. 11 Dynamic responses of three-level DTC for an induction motor
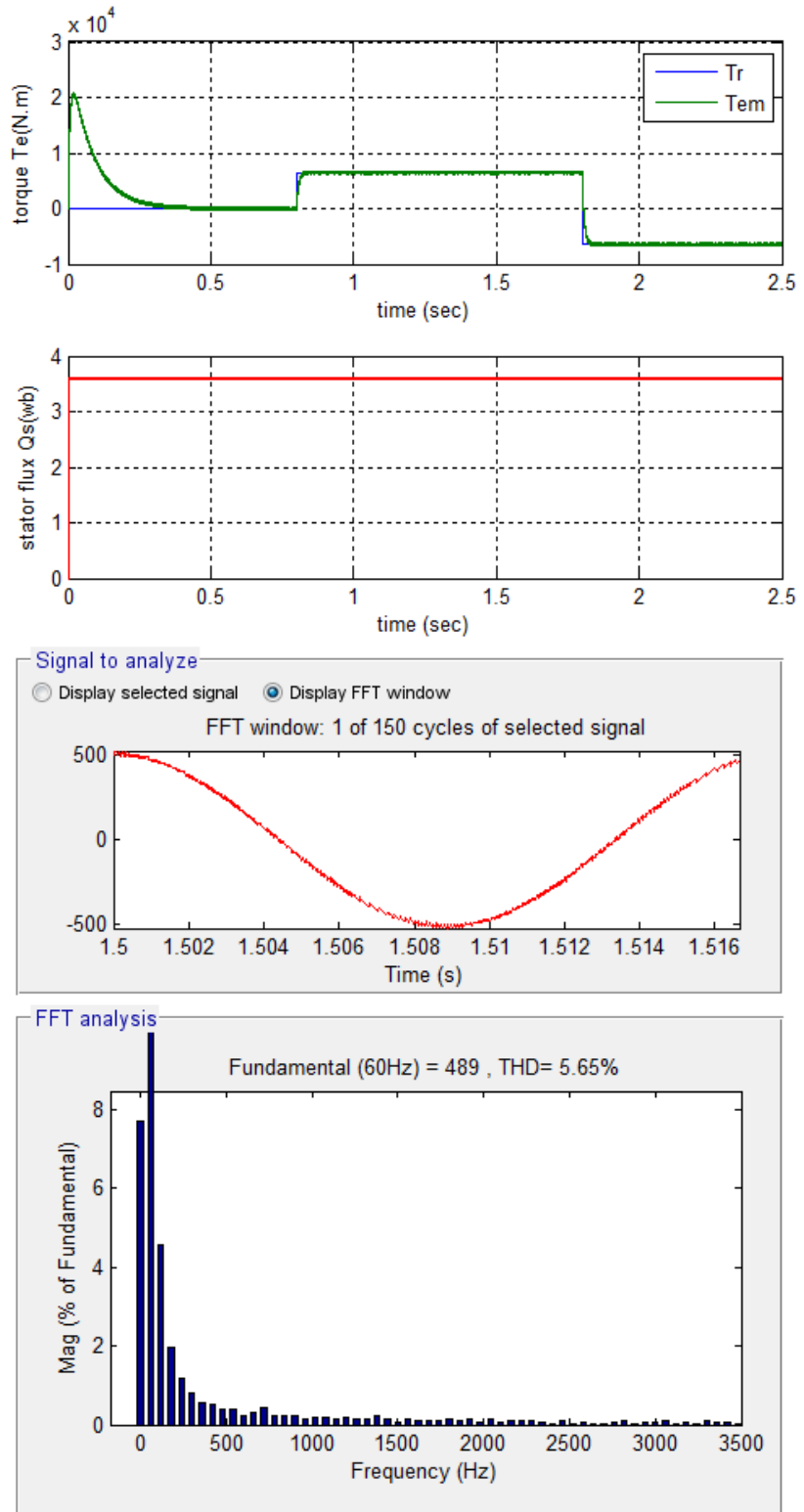

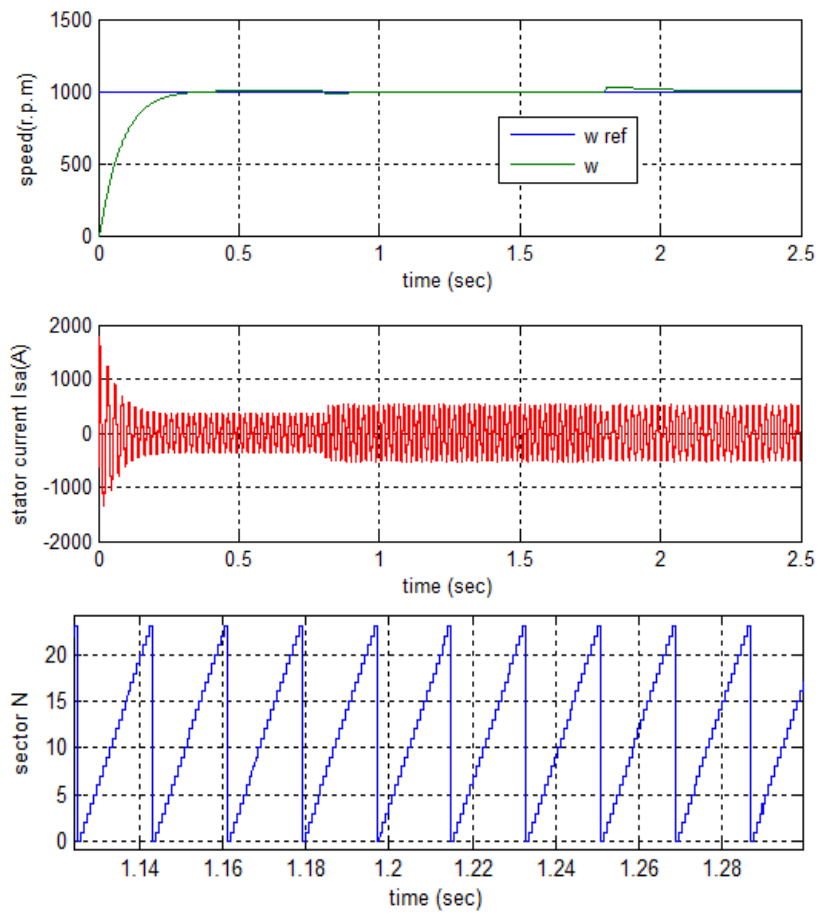

Fig. 12 Dynamic responses of three-level DTC with controller of speed and regulators hysteresis based in artificial intelligence techniques for an induction motor

The speed reaches its reference without overrun at empty start for all strategies. And the torque flow the load torque.

The dynamics of the components of the stator flux are not affected by the application of these load guidelines.

Torque and stator flux response comparing curves are shown in Fig. 13.

Fig. 13 shows the zoom results for motor torque and flux response for three-level DTC with and without artificial intelligence techniques for a reference speed of $1000 \mathrm{rpm}$. The motor is allowed to run without load torque. As observed,the transient and steady state ripple are high for three-level DTC without artificial intelligence techniques.

In Table 3, we summarize the simulation results obtained by conventional three-level DTC and the proposed control of three-level DTC with 24 sectors.
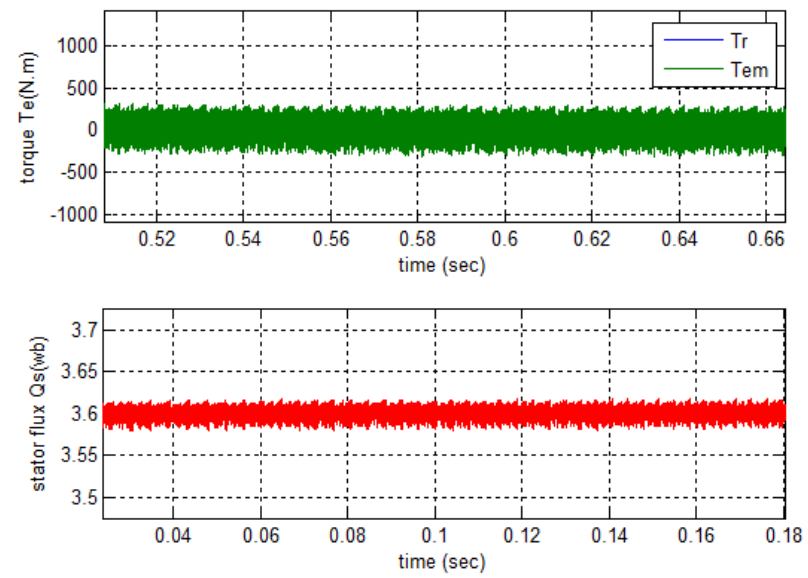

a)
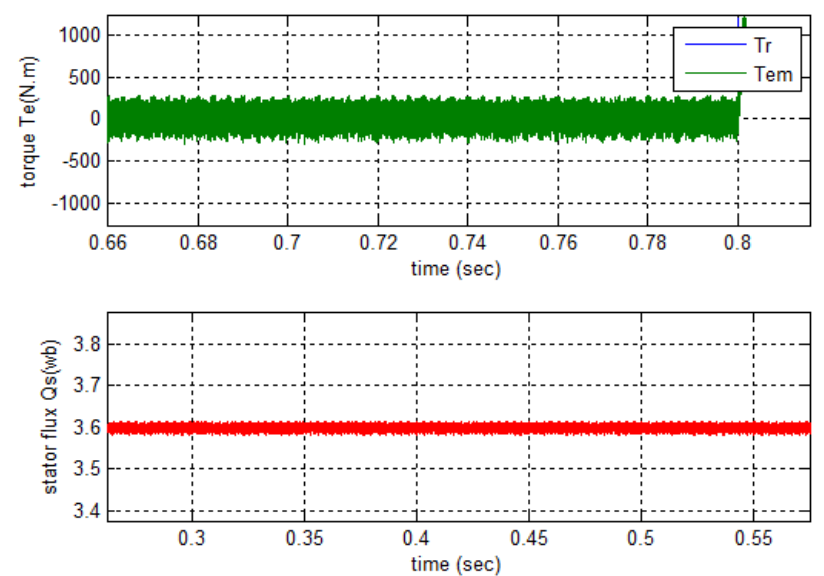

b)

Fig. 13 Zoom of torque and flux: a) Three-level DTC with 24 sectors, b) Three-level DTC with 24 sectors based on artificial intelligence techniques

Table 3 Comparaision between proposed controls

\begin{tabular}{|c|c|c|}
\hline Control & $\begin{array}{c}\text { Three-level } \\
\text { DTC } \\
\text { with 24 } \\
\text { sectors }\end{array}$ & $\begin{array}{c}\text { Three-level DTC } \\
\text { with 24 sectors } \\
\text { based on artificial } \\
\text { intelligence } \\
\text { techniques }\end{array}$ \\
\hline $\begin{array}{c}\text { Ias } \\
\text { THD (\%) }\end{array}$ & 8.06 & $\mathbf{5 . 6 5}$ \\
\hline $\begin{array}{c}\text { Dynamic } \\
\text { response of } \\
\text { flux (ms) }\end{array}$ & 4 & $\mathbf{3 . 7}$ \\
\hline
\end{tabular}

It can be seen that three-level DTC with 24 sectors based on artificial intelligence techniques, THD is low as compare to conventional three-level DTC.

\section{CONCLUSION}

The present paper has presented a sensorless speed three-level DTC drive 24 sectors with artificial intelligence techniques applied to an IM is presented, fuzzy logic and neural networks. This techniques determinates the desired amplitude of torque, flux hysteresis band and speed controller.

It is shown that the flux and torque responses under steady state condition. The main advantage is the improvement of torque and flux ripple characteristics at low speed region, this provides an opportunity for motor operation under minimum switching loss and noise.

\section{APPENDIX}

The parameters of 3 phase induction machine employed for simulation purpose is given below:

Table 4 Implementation parameters

\begin{tabular}{|l|c|}
\hline \multicolumn{1}{|c|}{ Parameters } & Values \\
\hline Nominal power & $1 \mathrm{Mw}$ \\
\hline Line to line voltage & $791 \mathrm{v}$ \\
\hline Frequency & $60 \mathrm{~Hz}$ \\
\hline Stator resistance & $0.228 \Omega$ \\
\hline Stator inductance & $0.0084 \mathrm{H}$ \\
\hline Rotor resistance & $0.332 \Omega$ \\
\hline
\end{tabular}




\begin{tabular}{|l|c|}
\hline Rotor inductance & $0.0082 \mathrm{H}$ \\
\hline Mutual inductance & $0.0078 \mathrm{H}$ \\
\hline Inertia & $20 \mathrm{Kg} . \mathrm{m}^{2}$ \\
\hline Friction & $0.008 \mathrm{~N} . \mathrm{m} . \mathrm{s}$ \\
\hline Number of poles & 3 \\
\hline
\end{tabular}

\section{REFERENCES}

[1] BENESSEK, F. - BOURBIA, W. - BENSAKER, B.: Flatness based non linear sensorless control of induction motor systems, International Journal of Power Electronics and Drive System (IJPEDS), Vol. 7, No. 1, pp. 265-278, March 2016.

[2] EL MEHDI, C. - AHMED, M. - ABDELKADER, M. - ABDERRAHMANE, G.: Sensorless direct torque control of induction machine with MRAS speed estimator, Computer Science and Engineering, 3 (1) pp. 8-13, 2013.

[3] RAMAHLINGAM, S. - BIN JIDIR, A. - SUTIKNO, T. - RAJ, L. L.: Improvise 3-level DTC of induction machine using constant switching frequency method by utilizing multiband carrier, International Journal of Power Electronics and Drive System (IJPEDS), Vol. 7, No. 3, pp. 638-647, September 2016.

[4] NAAS, B. - NEZLI, L. - NAAS, B. - MAHMOUDI, M. O. - ELBAR, M.: Direct torque control based three level inverter-feed double star permanent magnet synchronous machine, Sciverse, Science Direct, Energy Procedia 18 (2012), pp. 521-530.

[5] BENYOUSSEF, E. - MEROUFEL, A. - BARKAT, S.: Three-level DTC based on fuzzy logic and neural network of sensorless DSSM using extende kalman filtre, International Journal of Power Electronics and Drive System (IJPEDS), Vol. 5, No. 4, pp. 453-463, April 2015.

[6] SEBTI, B.: Commande par DTC d'un moteur asynchrone apport des réseaux de neurones, Mémoire de Magister, université de Batna, 2013.

[7] OTHMANE, E. - AISSA, D.: Etude de stratégies de commande pour la régulation des courants de la machine asynchrone, Mémoire de Master
Académique, université de Kasdi Merbah-Ouaragla, 2013.

[8] IDIR, A. - KIDOUCHE, M.: Direct torque control of three phase induction motor drive using fuzzy logic controllers for low torque ripple, Proceedings Engineering \& Technology, Vol. 2, pp. 78-83, 2013.

[9] VAHDATIFAR, N. - MORTAZAVI, S. KIANINEZHAD, R.: Neural network based predictive DTC algorithm for induction motors, International Journal of Computer, Electrical, Automation, Control and Information Engineering, Vol. 4, No. 11, 2011.

[10] BOUDJEMA, Z. - MEROUFEL, A. - BOUNADJA, E. - DJERRIRI, Y.: Nonlinear control of a doubly fed induction generator supplied by a matrix converter for wind energy conversion systems, Journal of Electrical Engineering (JEE), Vol. 14, No. 2, 2014.

[11] ABDELHAFIDH, M.: Stratégies de commande DTCSVM et DPC appliquées à une MADA utilisée pour la production d'énergie éolienne, Thèse de Doctorat, Ecole Nationale Polytechnique, Alger, 2014.

Received July 3, 2017, accepted November 24, 2017

\section{BIOGRAPHIES}

Habib Benbouhenni was born in chlef, Algeria. He is a $\mathrm{PhD}$ student in the Departement of Electrical Engineering at the ENPO-MA, Oran, Algeria. He received a M.S. degree in automatic and informatics industrial in 2017. His research activities include the application of robust command in the wind turbine power systems.

Zinelaabidine Boudjema was born in Algeria in 1983. $\mathrm{He}$ is teacher in university of chlef, Algeria. He received a M.S. degree in electrical engineering from ENP of Oran, Algeria in 2010. He received a $\mathrm{PhD}$ in Electrical Engineering from University of Sidi Belabes, Algeria 2015. His research activities include the study and application of robust control in the wind-solar power systems. 